\title{
Atmospheric Corrosion of Galvanized Steel and Precipitation Runoff from Zinc in a Marine Environment
}

\author{
Rosa Vera,* Fabián Guerrero, Diana Delgado and Raquel Araya \\ Instituto de Química, Facultad de Ciencias, Pontificia Universidad Católica de Valparaíso, \\ Av. Universidad 330, Placilla, Casilla 4059, Valparaíso, Chile.
}

\begin{abstract}
Este estudo focaliza o comportamento do aço galvanizado em um ambiente marinho corrosivo e no processo de escoamento superficial para o mesmo material que ocorrem em Valparaíso, Chile. O potencial de corrosão e a taxa de corrosão avaliados através de perda de massa foram utilizados para determinar os danos da corrosão para o aço galvanizado. As composições dos produtos de corrosão foram determinadas utilizando difratometria de raios X (XRD) e sua morfologia através da microscopia eletrônica de varredura (SEM). As soluções de escoamento coletadas após as chuvas foram analisadas para determinar o valor de $\mathrm{pH}$ e das concentrações dos íons $\mathrm{Cl}^{-}, \mathrm{SO}^{2-}$ e $\mathrm{Zn}^{2+}$. Os resultados após 15 meses mostram que o potencial de corrosão do aço galvanizado aumenta ao longo do tempo, indicando a formação de uma película protetora que consiste em produtos de corrosão de zinco. Estes produtos foram identificados como zincita e simoncoleita. Os valores de pH obtidos para as soluções de escoamento são semelhantes das amostras de água da chuva de referência, e as concentrações de cloreto das soluções de escoamento são aproximadamente duas vezes as da água de chuva
\end{abstract}

This study focuses on the behavior of galvanized steel in a corrosive marine environment and on the runoff process for the same material occurring in Valparaiso, Chile. The corrosion potential and corrosion rate evaluated via mass loss were used to determine the corrosion damage to the galvanized steel. The compositions of the corrosion products were determined using X-ray diffractometry (XRD), and their morphology through scanning electron microscopy (SEM). The runoff solutions collected after rainfall were analyzed to determine the $\mathrm{pH}$ value, and $\mathrm{Cl}^{-}$, $\mathrm{SO}_{4}{ }^{2-}$ and $\mathrm{Zn}^{2+}$ ion concentrations. The results after 15 months show that the corrosion potential of the galvanized steel increases over time, indicating the formation of a protective film that consists of zinc corrosion products. These products were identified as zincite and simonkolleite. The $\mathrm{pH}$ values obtained for the runoff solutions are similar to those of the reference rainwater samples, and the chloride concentrations of the runoff solutions are approximately twice those of the rainwater.

Keywords: atmospheric corrosion, galvanized steel, mass loss, runoff, chloride

\section{Introduction}

Atmospheric corrosion is the electrochemical deterioration of a metal due to atmospheric factors, both meteorological and chemical. Metals suffer losses due to spontaneous oxidation when their surfaces are wetted by a layer of condensed water due to fog or rain. This process leads to the formation of a protective film that acts as a physical barrier between the metal and the environment. ${ }^{1-5}$

Galvanization produces a zinc coating on a steel surface and is one of the most efficient methods for steel corrosion protection. This protection is due to the

*e-mail: rvera@ucv.cl excellent corrosion resistance of zinc coatings, particularly in atmospheric environments. Significant amounts of galvanized steel are used extensively in the construction industry for roofing, gutters, drainage pipes and hot-dip galvanized reinforcing steel rebars. ${ }^{6}$ The corrosion protection of galvanized steel depends on the thickness, porosity and adherence to steel of the zinc coating. It is also important to consider the nature of the corrosion products, the exposure time to aggressive media, the climatic factors and the atmospheric pollutants. ${ }^{7-9}$

When zinc is exposed to any environment, it immediately forms a fine film of zinc oxide ( $\mathrm{ZnO})$, which is an n-type semiconductor. The electronic conductivity of zinc oxide promotes oxygen reduction, which is a common cathodic 
corrosion reaction. ${ }^{10}$ Hydroxide radicals $\left(\mathrm{OH}^{-}\right)$from the oxygen reduction are adsorbed on the film, leading to the consolidation of a moisture layer thick enough to cause electrochemical reactions depending on the components $\left(\mathrm{Cl}^{-}, \mathrm{SO}_{x}, \mathrm{CO}_{2}\right.$, etc. $)$ found in the atmosphere. ${ }^{11-14}$

Because this study is performed in a marine atmosphere, it is important to consider the zinc corrosion products in this medium, which are simonkolleite $\left(\mathrm{Zn}_{5}(\mathrm{OH})_{8} \mathrm{Cl}_{2} \cdot \mathrm{H}_{2} \mathrm{O}\right)$, hydrozincite $\left(\mathrm{Zn}_{5}\left(\mathrm{CO}_{3}\right)_{2}(\mathrm{OH})_{6}\right)$ and zinc and sodium hydroxyl-chlorosulfate $\left(\mathrm{NaZn}_{4} \mathrm{Cl}(\mathrm{OH})_{6} \mathrm{SO}_{4} \cdot 6 \mathrm{H}_{2} \mathrm{O}\right)$. Simonkolleite is the most commonly formed product within a few days of exposure. The hexagonal structure of simonkolleite is discontinuously distributed as "islands" on the metal surface, and the stability of this compound depends on the chloride ion concentration and the $\mathrm{pH}$ value of the environment. ${ }^{15-18}$

These corrosion products include zinc chloride $\left(\mathrm{ZnCl}_{2}\right)$ and zinc sulfate $\left(\mathrm{ZnSO}_{4}\right)$, which are not adherent and can be physically removed from the metal surface (by wind or sand erosion) or dissolved by rain or condensation. The release of zinc ions into a medium due to the dissolution of soluble corrosion products is termed runoff. This process depends on the volume, intensity, flow rate, frequency and $\mathrm{pH}$ of local rainfall. Besides metal ions, runoff solutions can contain chemical compounds that are present in the air and have been deposited onto the metal surface before the rainfall, including dissolved organic matter or matter in a suspension. As a consequence of the runoff process, traces of metals can be found in soil and in water supplies, which can pose a significant ecological risk. ${ }^{19-22}$

This study focuses on the behavior of galvanized steel under atmospheric corrosion in a marine environment and presents the first results for the effects of runoff processes on zinc under these conditions in Chile.

\section{Experimental}

Initial state of the hot-dip galvanized steel

Steel plates were hot-dipped in a galvanizing bath composed of $0.005 \% \mathrm{Al}, 0.35 \% \mathrm{Sn}, 0.30 \% \mathrm{~Pb}, 0.5 \% \mathrm{Ni}$ and $\mathrm{Zn}$, which formed the remaining percentage. Figure 1a shows the surface appearance of the galvanized steel, which exhibits a certain degree of porosity in the $\mathrm{Zn}$ coating, while Figure $1 b$ shows the energy dispersive spectrometer (EDX), indicating a principal element composition of 95.8\% $\mathrm{Zn}, 0.65 \% \mathrm{Fe}, 2.91 \% \mathrm{~Pb}$ and $1.47 \% \mathrm{Al}$. Previous results obtained by the authors show a cross-section with a $\mathrm{Zn}$ coating $(\eta)$ approximately $30 \mu \mathrm{m}$ thick and with other layers $80 \mu \mathrm{m}$ thick, though only the $\zeta$ phase $\left(\mathrm{FeZn}_{13}\right)$ is visible. ${ }^{16,23}$

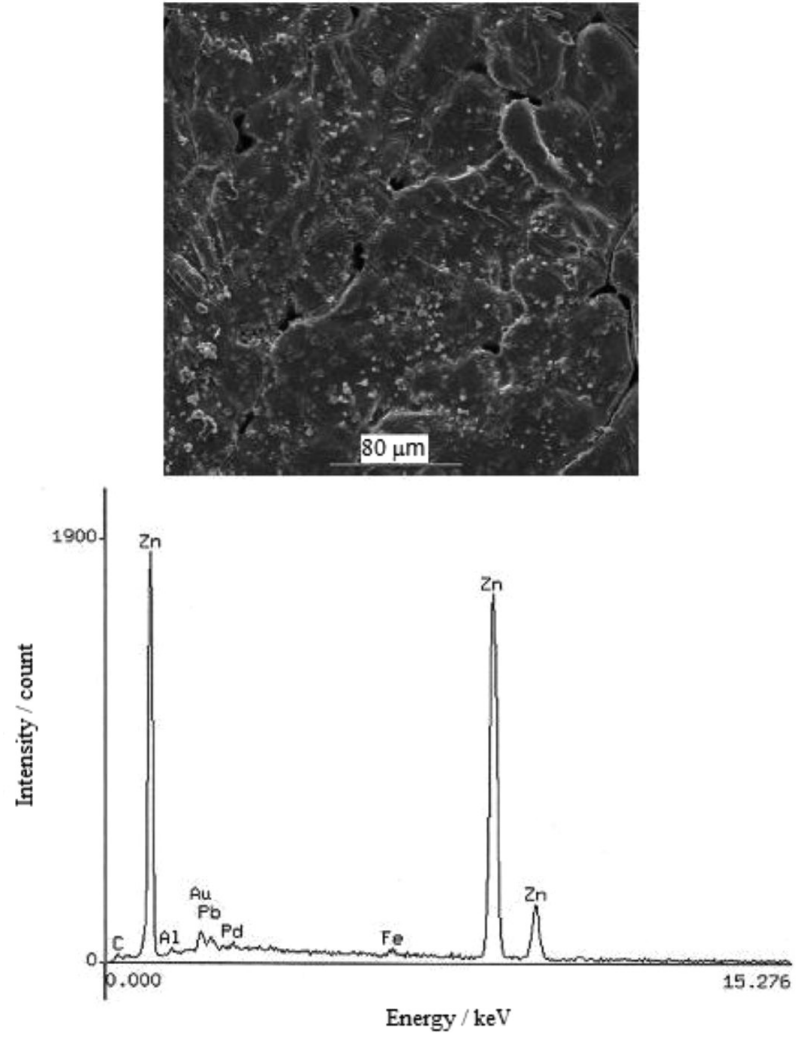

Figure 1. Initial SEM image and EDX spectrum of the galvanized steel $(500 \times)$.

\section{Sample preparation and installation}

During the studied period from January 2008 to March 2009, samples of hot-dip galvanized steel $100 \times 100 \times 6 \mathrm{~mm}$ in size were exposed at an atmospheric station located in Valparaiso (Lat. $32^{\circ} \mathrm{S}$, Long. $71^{\circ} \mathrm{W}$ ), Chile, $170 \mathrm{~m}$ from the coast and $11 \mathrm{~m}$ above sea level. The galvanized steel test plates were given an initial average $\mathrm{Zn}$ coating $114.0 \pm 0.1 \mu \mathrm{m}$ thick and were degreased, washed, dried, weighed and then stored in a moisture-free environment until use.

The samples were prepared in triplicate and installed on a panel with a $45^{\circ}$ angle to the horizontal and with their faces oriented towards marine fog, in accordance with $\mathrm{ISO}^{24}$ and $\mathrm{ASTM}^{25}$ standards. For the runoff test, 16 samples were mounted above plastic gutters connected to tubes that led to a $5 \mathrm{~L}$ storage receptacle, which collected the runoff solution for subsequent chemical analysis after each rainfall episode. Separate rainwater samples were also collected during each episode as references.

\section{Meteorological and environmental measurements}

The meteorological parameters that were measured on a monthly basis at the atmospheric station are as follows: 
relative humidity, temperature, time of wetness, rainfall amount and wind speed. To determine the amount of chloride and sulfur dioxide in the atmosphere, the wet candle technique was used in accordance with the ISO 9225 standard. ${ }^{26}$

\section{Corrosion testing}

The rate of corrosion was determined using the mass loss of the triplicate test plates after 3, 6, 9, 12 and 15 month exposures, in accordance with the ISO 8407 standard. ${ }^{27}$ Similarly, the in situ corrosion potential was measured periodically in accordance with the Pourbaix methods using a Radiometer pIONeer 10 high impedance millivoltmeter and an agar/KCl bridge electrode holder, which was fitted with a saturated calomel reference electrode designed especially for measurements of metal surfaces. Each time, the corrosion potential was measured for a sample, 10 measurements were taken, and the average was calculated.

The morphology of the corrosion was observed using a JEOL JSM-5410 scanning electron microscope coupled to an EDX 9100 energy dispersive spectrometer, and the corrosion products obtained on the galvanized steel were identified using a X'PERT PRO PANalytical diffractometer with a $\mathrm{Cu} \mathrm{K}_{\alpha}$ radiation and a pyrolytic graphite monochromator. The equipment power was $40 \mathrm{~mA}$ and $40 \mathrm{kV}$ in the grazing beam mode with an angle of incidence of 1 degree and a nickel filter.

\section{Runoff solution analysis}

For the runoff solutions collected after each rainfall episode, $\mathrm{pH}$ and conductivity measurements were taken as well as triplicate measurements of the $\mathrm{Cl}^{-}, \mathrm{SO}_{4}{ }^{2-}$ and $\mathrm{Zn}^{2+}$ ion content. The same parameters were measured for the reference rainwater samples.

The level of $\mathrm{Zn}^{2+}$ was determined from atomic absorption spectroscopy using a Shimadzu AA 6800 F with a direct aspirator and air-acetylene burner. The level of chloride was determined using a modified Mohr's method, which is a standard water analysis: ${ }^{28}$ the $\mathrm{pH}(7-10)$ of a known sample is altered by the addition of a NaOH $0.1 \mathrm{~mol} \mathrm{~L}^{-1}$ and $\mathrm{H}_{2} \mathrm{SO}_{4} 0.05 \mathrm{~mol} \mathrm{~L}^{-1}$. Next, $1 \mathrm{~mL}$ of a potassium chromate indicator solution is added, and a silver nitrate solution is used to evaluate the amount of chloride in the sample. A blank test is also conducted to determine the amount of reagent consumed by the indicator.

The sulfate content was determined using the gravimetric method specified in the Standard Methods for the Examination of Water and Wastewater. ${ }^{29}$ The sulfate ion content of a known volume of runoff solution is determined by precipitating the solution with $10 \% \mathrm{~m} / \mathrm{v}$ barium chloride. The obtained barium sulfate filtrate is dried until a constant mass is reached; it is then cooled and weighed on an analytical balance with a precision of $\pm 0.0001 \mathrm{~g}$.

Measurement of the $\mathrm{pH}$ value was conducted using a Scholar $\mathrm{pH}$ meter with a combined glass OKCN electrode, while the conductivity was measured using a Jenway 4071 conductometer with an electrode of the same make.

\section{Results and Discussion}

\section{Characterization of the test atmosphere}

Monthly evaluation of the climatic and environmental parameters and the application of the ISO 9223 standard $^{30}$ enabled the classification of the atmospheric aggressiveness categories at the station. Figures $2 a-2 c$ show the variations

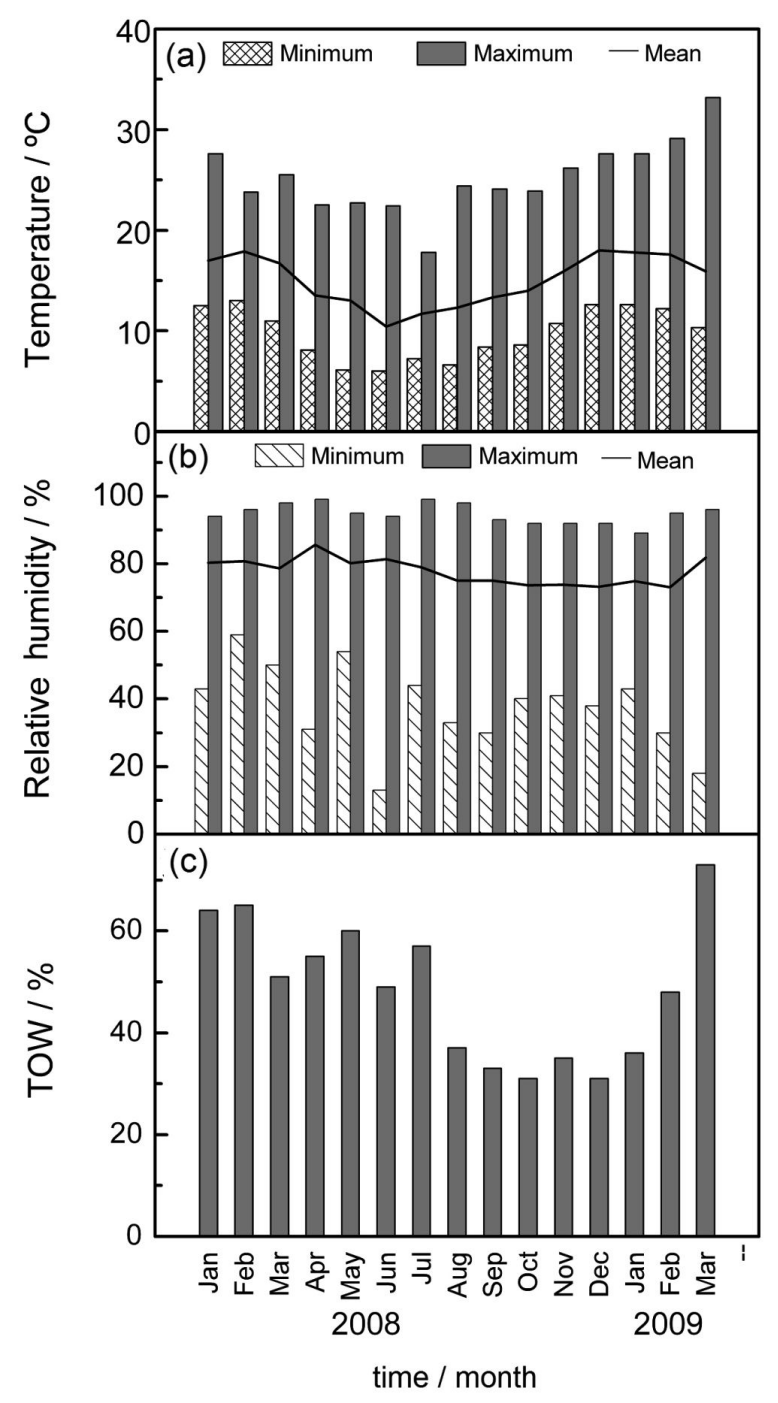

Figure 2. Meteorological parameters in the environment: (a) temperature, (b) relative humidity and (c) time of wetness (TOW). 
in the temperature, relative humidity and time of wetness $(\tau)$ during the study period, and Figure 3 shows the variations in the atmospheric deposition of chloride (salinity, S) and sulfur dioxide (sulfated compounds, P).

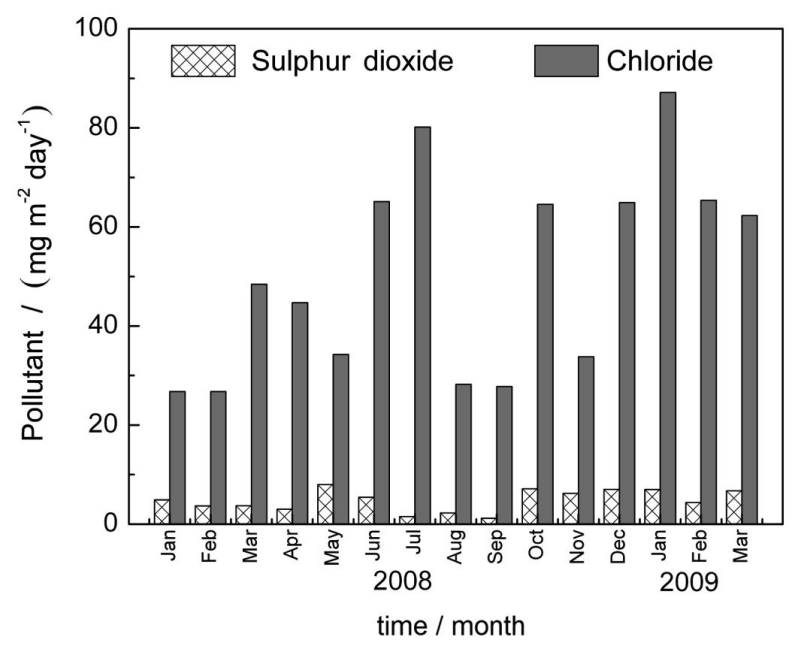

Figure 3. Monthly deposition rate of chloride and $\mathrm{SO}_{2}$ in the environment.

The time of wetness (TOW) is the sum of all of the times when moisture is present on the metal surface, during which corrosion is possible. In this case, TOW reached an average of $48.3 \%$, indicating category $\tau_{4}$. This value is higher during the first months of the year due to the coastal cloud cover during Summer (trough) that can last the entire day, which maintains the sample moisture and brings saline fog from the coast. It is therefore expected that the corrosion process on the galvanized steel depends mainly on the chloride content and TOW.

With regard to chloride ions, the average level is $52.4 \mathrm{mg} \mathrm{m}^{-2}$ day $^{-1}$, corresponding to category $\mathrm{S}_{1}$. The sulfated compound deposits reached an average of $4.8 \mathrm{mg} \mathrm{m}^{-2}$ day ${ }^{-1}$, i.e., a category of $\mathrm{P}_{0}$. Based on these results, the atmospheric station can be classified in accordance with the ISO 9223 standard $^{30}$ as C3, which corresponds to a medium corrosivity, meaning the general corrosion of $\mathrm{Zn}$ when the main aggressive agent is the $\mathrm{Cl}^{-}$ ion, and is the principal characteristic of an atmospheric station located near the coast.

Rainfall is an important factor in the runoff process. Figure 4a shows the amount of rainfall during the studied period, which averaged $652.0 \mathrm{~mm} \mathrm{month}{ }^{-1}$. The months of May and August have the highest rainfall, 253.81 and $216.07 \mathrm{~mm} \mathrm{month}^{-1}$, respectively. March shows the least rainfall, with $8.7 \mathrm{~mm} \mathrm{month}^{-1}$, and the first rainfall of the year occurs during this month. During the 15 month study period, 40 days have rainfall and 410 days do not.

Figure $4 \mathrm{~b}$ shows the variations in the wind speed. This parameter is important because the speed, origin and

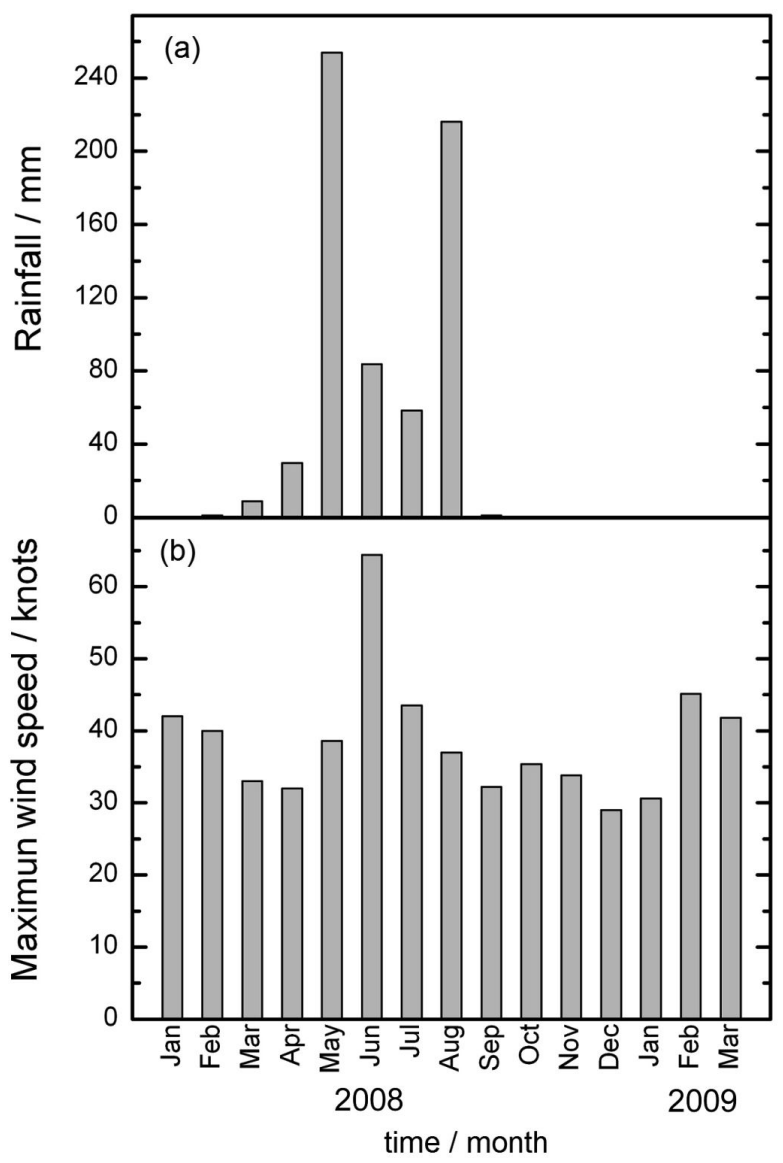

Figure 4. Monthly rain and wind speed measured in the test environment.

direction of the wind influence the amount of pollutants in the air, the chemical composition of the rainwater and the speed of the test plate drying process, which affects the time of wetness. During the studied period, a direct relation can be observed between the speed and direction of the wind and the amount of atmospheric chloride deposited on the metal surface. This result arises because the increase in the coastal wind raises the salt content of the marine spray moving inland, which is predominantly in a Southeastern direction.

\section{Corrosion of galvanized steel as a function of time}

The $\mathrm{Zn}$ mass loss during steel exposure to a marine environment is shown in Figure 5a for the 15 month studied period.

After the first three months of exposure, the corrosion of the material leads to a $\mathrm{Zn}$ mass loss of $2.0 \pm 0.3 \mathrm{mg} \mathrm{cm}^{-2}$ and to the initial formation of corrosion products on the metal surface. These products are predominantly compounds with specific degrees of adhesion and compatibility, such as the simonkolleite $\left(\mathrm{Zn}_{5}(\mathrm{OH})_{8} \mathrm{Cl}_{2} \cdot \mathrm{H}_{2} \mathrm{O}\right)$ and zincite $(\mathrm{ZnO})$ that were observed in the XRD diffractogram (Figure 6), and soluble products, such as $\mathrm{ZnCl}_{2}$ and $\mathrm{ZnSO}_{4}$, that are later 
leached by the rainfall and detected in subsequent runoff solutions. During this first exposure period, the total rainfall was minimal $(8.7 \mathrm{~mm})$.
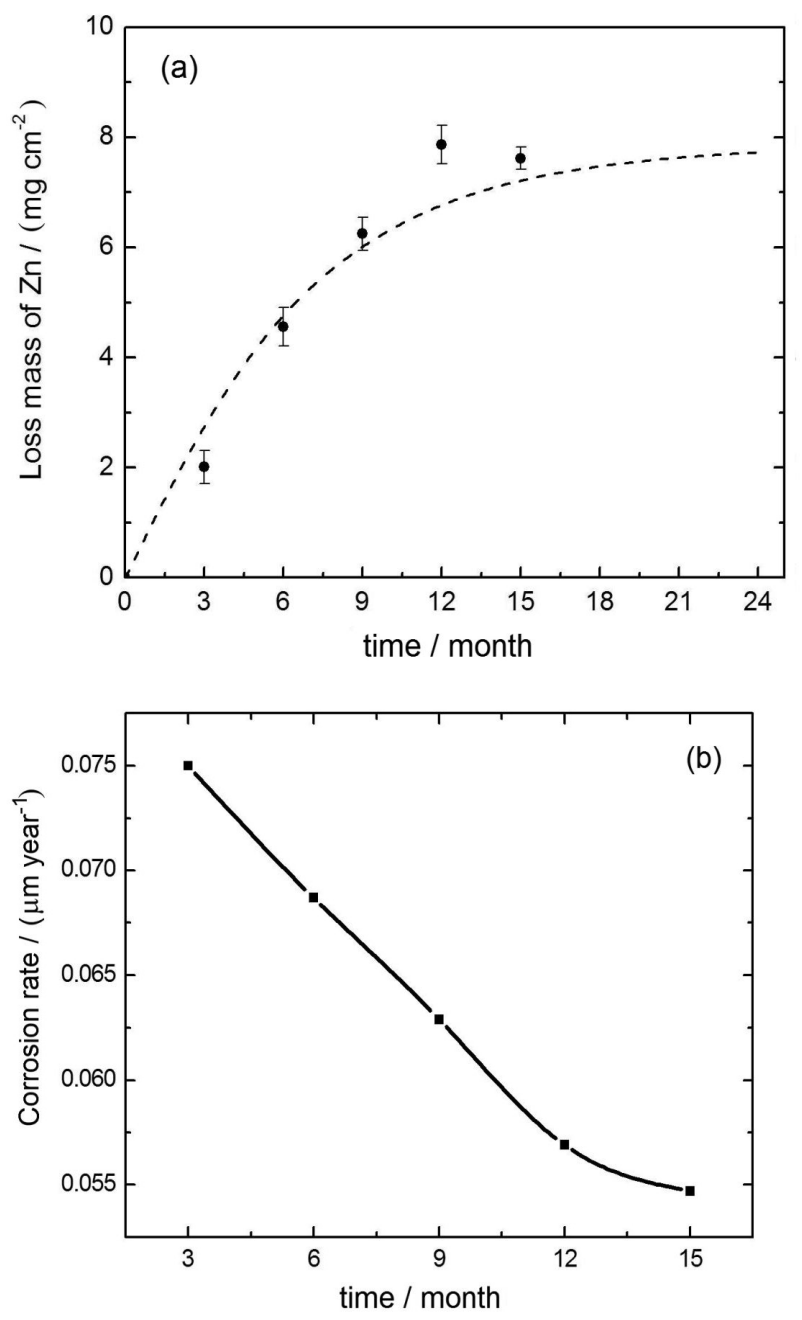

Figure 5. (a) Mass loss over 15 month exposure $(\bullet)$ and exponential projection of mass loss to 24 months ( --- ), and (b) corrosion rate over time.

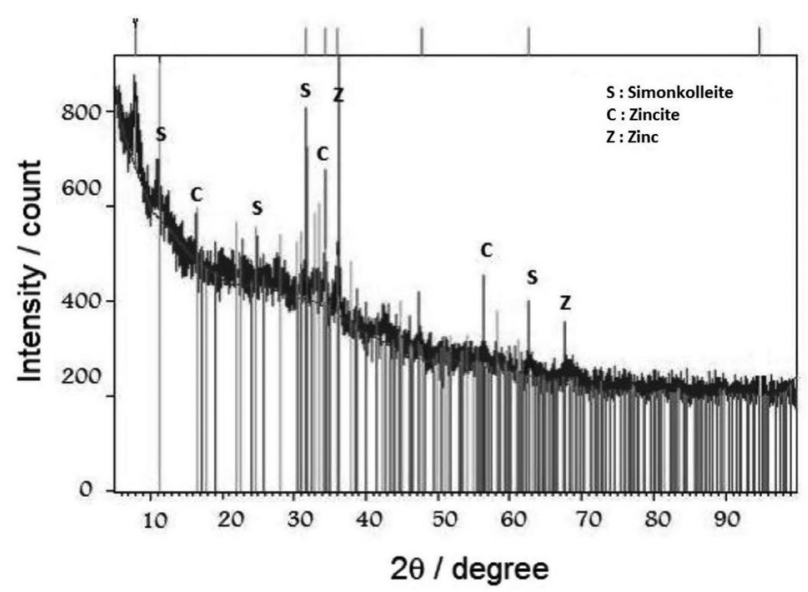

Figure 6. XRD pattern of the corrosion products on the galvanized steel at 3 months.
The second evaluation after 6 months of exposure covers the period of highest rainfall $(367 \mathrm{~mm})$, leading to an increased leaching of the soluble products and deposited salts, an enhancement in the runoff process and a more than twofold increase in the metal mass loss, which reached a value of $4.6 \pm 0.4 \mathrm{mg} \mathrm{cm}^{-2}$. After 9 months of exposure, the mass loss continues to rise, but to a lesser extent, and, in the following evaluation periods, the mass loss tends towards a constant value over time, exhibiting an exponential relation. Furthermore, the corrosion rate decreases over time, tending towards the passivity of the galvanized steel under these conditions. This result corroborates the mass loss behavior of the galvanized steel over time (Figure 5b) and is contrary to those of other authors in which the corrosion process accelerates over time due to the runoff effect. ${ }^{9,18}$

This behavior can be explained by the lack of rainfall impeding the leaching of the soluble products and by the insoluble corrosion products, which were formed over time, acting as a physical barrier between the metal and the environment.

Based on the obtained data, the $\mathrm{Zn}$ mass loss would reach a value of $7.7 \pm 0.6 \mathrm{mg} \mathrm{cm}{ }^{-2}$ after 24 months of exposure (Figure 5a), assuming that the meteorological and pollutant variables show no significant variations that would lead to a larger mass loss of the corrosion products that formed during the studied period.

\section{Corrosion potential as a function of time}

A possible method for confirming the presence of corrosion products on a metal surface is to measure the in situ corrosion potential, which should be more positive for a metal surface with corrosion products than for bare metal, depending on the thickness, morphology and composition of the corrosion products. The results obtained in this study show that the corrosion potential of the bare metal at the beginning of the exposure reaches a value of $-1000 \pm 20 \mathrm{mV} v s$. SCE, and over time, this value moves towards more positive values, reaching $-600 \pm 25 \mathrm{mV}$ vs. SCE after 15 months of exposure. The authors have previously described the same trend for the variation in the corrosion potential over time. ${ }^{16}$

The increase in the in situ corrosion potential of $400 \mathrm{mV}$ over time corroborates the presence of corrosion products, which act as a protective film on the metal surface and hinder the spread of species that intervene in the corresponding electrochemical reactions. This behavior is in agreement with the results described above for the $\mathrm{Zn}$ mass loss of the galvanized steel, in which the corrosion rate in the later periods does not increase linearly but rather tends towards a constant value. 
Analysis and morphology of the corrosion products

The visual evaluation of the galvanized steel $\mathrm{Zn}$ surface shows that white corrosion products adhere to the metal surface during exposure to the test conditions.

After three months of exposure, the galvanized steel exhibits a surface with corrosion products (Figure 7a), which are identified as zincite $(\mathrm{ZnO})$ and simonkolleite $\left(\mathrm{Zn}_{5}(\mathrm{OH})_{8} \mathrm{Cl}_{2} \cdot \mathrm{H}_{2} \mathrm{O}\right)$ via $\mathrm{X}$-ray diffraction (Figure 6$)$. The latter can be seen mainly in the micrograph (Figure $7 \mathrm{~b}$ ) as platelets with a lamellar shape. EDX analysis indicates that the principal elements of the semi-quantitative composition of the corrosion products (Figure 7c) are $\mathrm{O} 3.5 \%, \mathrm{Cl} 12.6 \%$, $\mathrm{Zn} 80.0 \%$ and $\mathrm{Si} 1.5 \%$. Si is usually found in corrosion products that come from soil during outdoor tests. These results agree with those obtained in other studies in which the formation of simonkolleite is enhanced by the presence of atmospheric chloride..$^{30-32}$
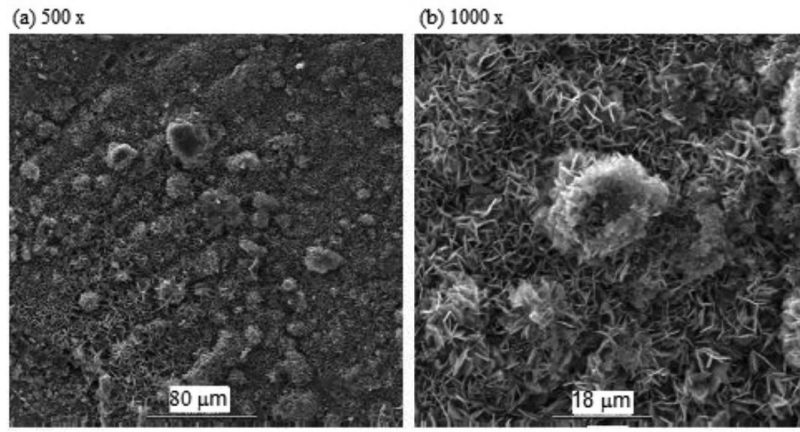

(c)

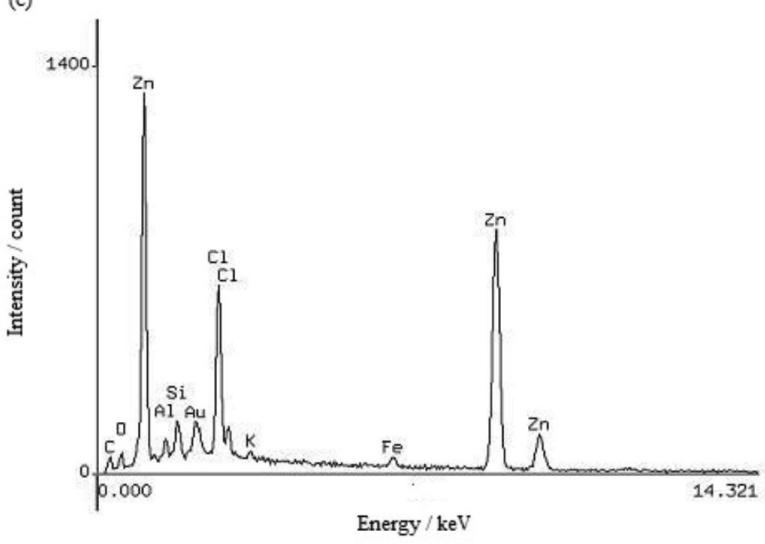

Figure 7. Morphology of the corrosion products on the galvanized steel after a 3 month exposure: SEM images ((a) $500 \times$ and (b) $1000 \times$ ) and (c) EDX spectrum $(2000 \times)$.

During the exposure of the galvanized steel samples to the marine atmosphere, the anodic dissolution of $\mathrm{Zn}$ (equation 1) is balanced by the reduction of $\mathrm{O}_{2}$ (equation 2) in the cathodic areas.

As a result of the ion deposits on the metal surface, the $\mathrm{Na}^{+}$cations (aq.) migrate towards the cathodic areas, while the $\mathrm{Cl}^{-}$anions (aq.) move towards the $\mathrm{Zn}$ dissolution sites, in which insoluble simonkolleite (equation 3 ) has formed as islands on the metal surface and in which the simonkolleite stability, as shown in the Pourbaix diagram, ${ }^{33}$ exhibits an intermediate $\mathrm{pH}$ level and a high $\mathrm{Cl}^{-}$activity. In the cathodic areas, in which the chloride activity on the metal surface is low and the $\mathrm{pH}$ value is high, $\mathrm{ZnO}$ tends to form. Therefore, the stability of these products on the galvanized steel surface will slow the $\mathrm{Zn}$ corrosion, and the corrosion rate will decrease with exposure time, as shown by the $\mathrm{Zn}$ behavior in Figure $5 \mathrm{~b}$.

$\mathrm{Zn}_{(\mathrm{s})} \rightarrow \mathrm{Zn}^{2+}{ }_{(\mathrm{aq})}+2 \overline{\mathrm{e}}$

$1 / 2 \mathrm{O}_{2(\mathrm{~g})}+\mathrm{H}_{2} \mathrm{O}_{(\mathrm{l})}+2 \overline{\mathrm{e}} \rightarrow 2 \mathrm{OH}^{-}{ }_{(\mathrm{aq})}$

$4 \mathrm{ZnO}_{(\mathrm{s})}+\mathrm{Zn}^{2+}{ }_{(\mathrm{aq})}+5 \mathrm{H}_{2} \mathrm{O}+2 \mathrm{Cl}^{-}{ }_{(\mathrm{aq})} \rightarrow$

$\mathrm{Zn}_{5}(\mathrm{OH})_{8} \mathrm{Cl}_{2} \cdot \mathrm{H}_{2} \mathrm{O}_{(\mathrm{s})}$

With an increase in exposure time, the insoluble corrosion products (simonkolleite and zincite) predominate on the metal surface, as do the soluble corrosion products $\mathrm{ZnCl}_{2}$ and $\mathrm{ZnSO}_{4}$, which have formed in the absence of rainfall and which will be dissolved (partially or totally) during each rainfall episode.

After 6 months of exposure, the galvanized steel is exposed to the months with the highest amounts of rainfall. The surface appearance of the steel (Figure 8a) shows that the soluble corrosion products formed by salt deposits are leached by the rainfall. Figure $8 \mathrm{~b}$ shows the globular morphology of the corrosion products, whose principal elements in the semi-quantitative composition are $\mathrm{Zn}$ $81.2 \%, \mathrm{Fe} 1.9 \%, \mathrm{Cl} 2.5 \%, \mathrm{~S} 2.9 \%$ and $\mathrm{O} 7.6 \%$, as analyzed by EDX (Figure $8 \mathrm{c}$ ). The main corrosion products identified are simonkolleite $\left(\mathrm{Zn}_{5}(\mathrm{OH})_{8} \mathrm{Cl}_{2} \cdot \mathrm{H}_{2} \mathrm{O}\right)$ and zincite $(\mathrm{ZnO})$.

After 12 months of exposure (Figure 9a), the corrosion products exhibit accumulated particles with a globular morphology (Figure 9b), whose principal elements in the semi-quantitative composition are $\mathrm{Zn} 65.0 \%$, $\mathrm{Fe} 1.5 \%, \mathrm{Cl} 5.9 \%, \mathrm{~S} 2.5 \%, \mathrm{~K} 4.21 \%$, Ca $8.1 \%, \mathrm{Mg}$ $1.6 \%, \mathrm{Al} 1.69 \%$ and $\mathrm{O} 5.58 \%$, as analyzed by EDX (Figure 9c). The XRD analysis identified the following corrosion products: simonkolleite $\left(\mathrm{Zn}_{5}(\mathrm{OH})_{8} \mathrm{Cl}_{2} \cdot \mathrm{H}_{2} \mathrm{O}\right)$, zincite $(\mathrm{ZnO})$, and, to a lesser degree, zinc and sodium chlorohydroxysulfate $\left(\mathrm{NaZn}_{4} \mathrm{Cl}(\mathrm{OH})_{6} \mathrm{SO}_{4} \cdot \mathrm{H}_{2} \mathrm{O}\right)$, which is formed by the incorporation of sulfate ions (via ionic exchange) into the crystalline structure of simonkolleite. ${ }^{14,30}$

\section{Analysis of the runoff solution}

From March-August 2008 (Figure 4a), different rainfall intensities were measured. The total amount of rainfall was $652.2 \mathrm{~mm}$ year $^{-1}$, and March was the month with the least 
rainfall $(8.7 \mathrm{~mm})$ and May the most rainfall $(253.8 \mathrm{~mm})$. During this period, 10 rainfall events were registered; the

(a) $500 \mathrm{x}$

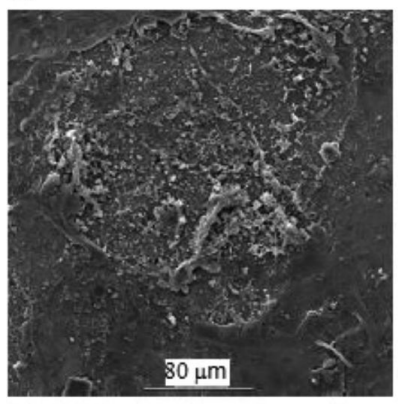

(b) $1000 \mathrm{x}$

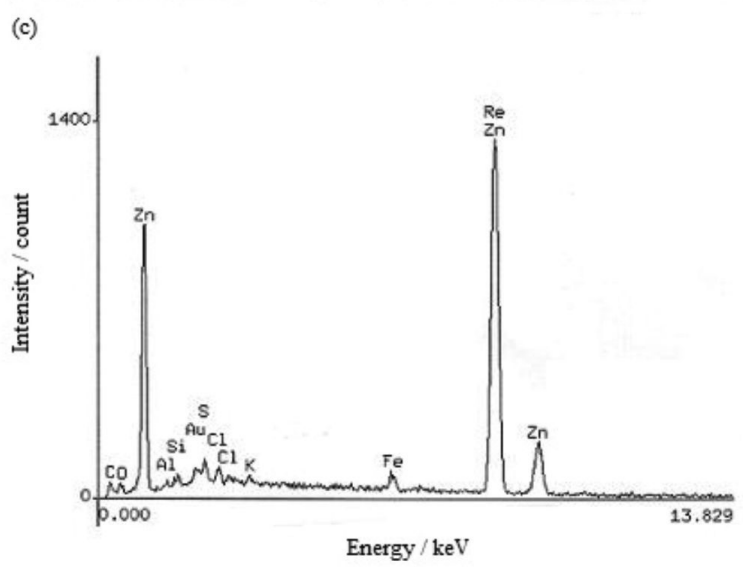

Figure 8. Corrosion products on the galvanized steel after a 6 month exposure: SEM images ((a) $500 \times$ and (b) $1000 \times$ ) and (c) EDX spectrum $(2000 \times)$.

(a) $500 x$

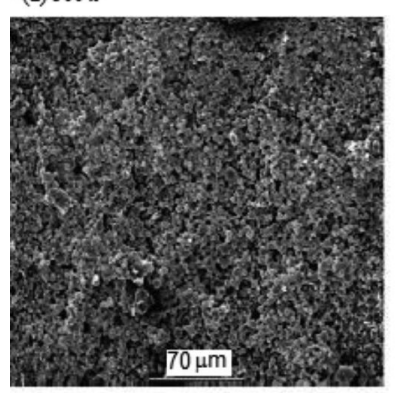

(c)

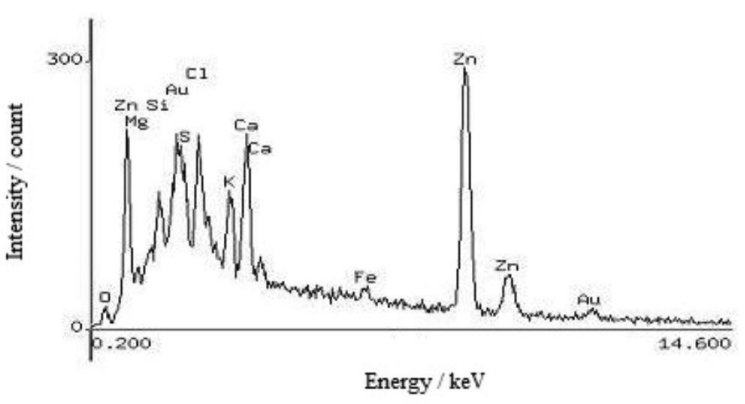

Figure 9. Corrosion products on the galvanized steel after a 12 month exposure: SEM images ((a) $500 \times$ and (b) $1000 \times$ ) and (c) EDX spectrum $(2000 \times)$. first occurred at 43 days of exposure and the second at 93 days of exposure (Figure 10). The period between these two events represents the longest dry period, but this period had a relative humidity above $80 \%$ (Figure $2 \mathrm{a}$ ), TOW of 0.55 (Figure 2c) and chloride content of approximately $40 \mathrm{mg} \mathrm{m}^{-2}$ day $^{-1}$ (Figure 3), which led to the formation of corrosion products due to the deposition of atmospheric pollutants, mainly $\mathrm{Cl}^{-}$and, to a lesser degree, $\mathrm{SO}_{2}$.

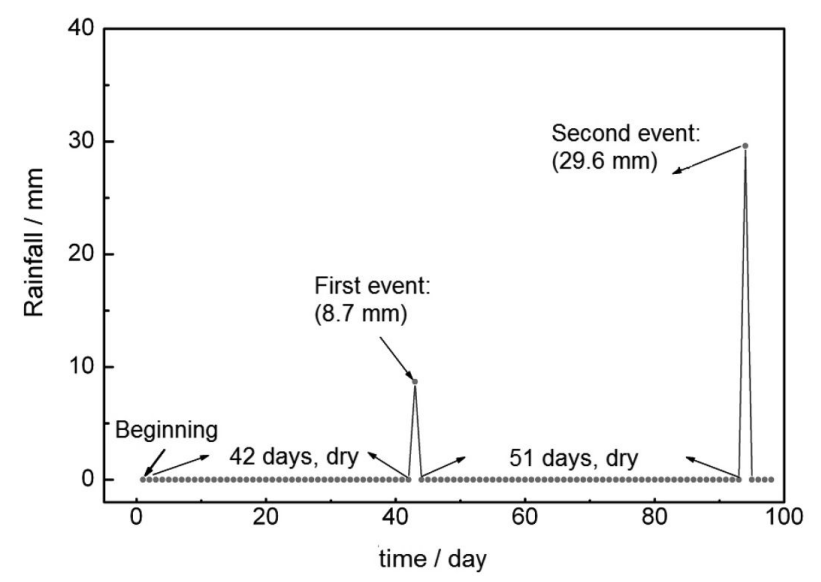

Figure 10. First rainfall events on the exposed zinc samples.

These pollutants encourage the formation of salts, such as simonkolleite $\left(\mathrm{Zn}_{5}(\mathrm{OH})_{8} \mathrm{Cl}_{2} \cdot \mathrm{H}_{2} \mathrm{O}\right.$, which can be dissolved by lightly acidic rainfall), and soluble products, such as $\mathrm{ZnCl}_{2}$ and $\mathrm{ZnSO}_{4}$ (which are partially or totally leached depending on the intensity of the rain). Thus, these pollutants contribute to the increased concentration of chloride and sulfate ions in the runoff solutions. The other rainfall events occurred with greater frequencies and with differing intensities up to the month of August 2008.

The average $\mathrm{pH}$ values measured for the 16 runoff solution samples from different rainfall events are shown in Figure 11a and compared with the reference rainwater samples. The $\mathrm{pH}$ values for the runoff solutions are similar to those for the rainwater samples and vary between $\mathrm{pH} 6.1$ and 7.1. These $\mathrm{pH}$ values corroborate the stability of simonkolleite on the metal surface, which forms a protective barrier against the atmospheric medium.

Figure $11 \mathrm{~b}$ shows the results obtained for the average conductivity of the samples, which were measured during the respective rainfall events. The runoff solution conductivity of the first episode is 4 times higher than that of the corresponding rainwater, which confirms the runoff process and corroborates the existence of soluble salts. This increase in conductivity is due to the period without rainfall (42 days), which leads to the accumulation of pollutant deposits on the metal surface. It can be seen that the conductivity of the runoff solution increases proportionally 


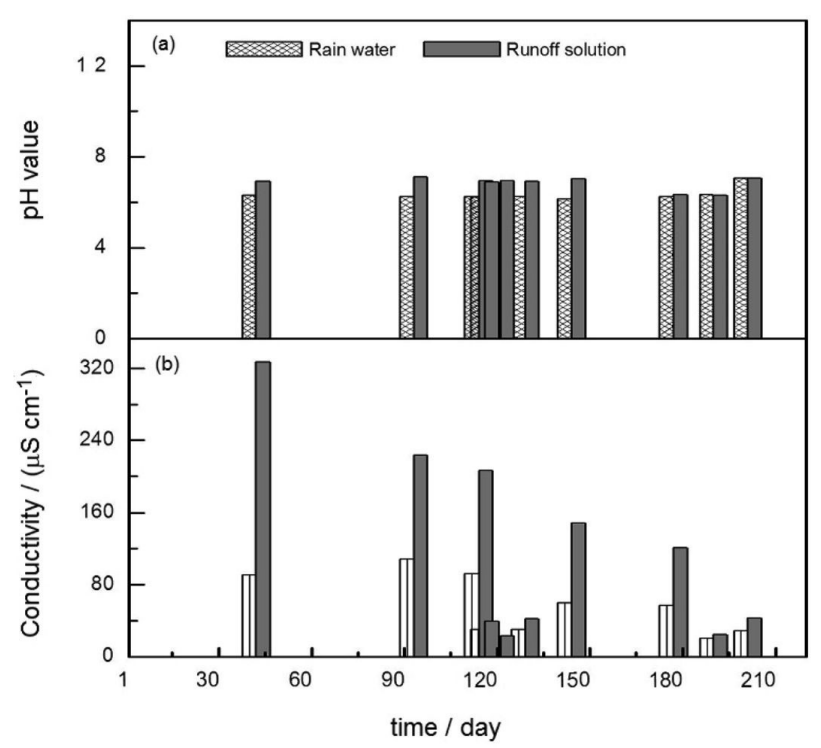

Figure 11. (a) $\mathrm{pH}$ value and (b) conductivity measured in the rainwater and runoff solutions for each rain event.

to the number of dry days that precede the rainfall and that the conductivity values are at their lowest and closest to the reference rainwater values in the months with continuous rainfall.

The results for the chloride and sulfate measurements obtained in the respective events are shown in Figure 12a. The chloride concentration in the runoff solution is approximately twice that in the rainwater for almost all rainfall episodes due to the retention of chloride on the metal surface (adsorbed/deposited or part of the corrosion products), which corroborates the runoff process. During the first rainfall event, however, the amount of chloride in the runoff solution is approximately six times that in the rainwater due to the prolonged dry period.

Additionally, Figure 12b shows that the sulfate concentrations in the runoff solutions are higher than those in the rainwater. In the runoff solutions, the chloride ion concentration is considerably higher than the sulfate concentration, which is most likely due to the location of the station and its proximity to the sea (the amount of atmospheric chloride $>$ atmospheric $\mathrm{SO}_{2}$ ). The higher chloride concentration in the runoff solution is partly due to the chlorides deposited on the metal surface by the sea breeze during dry periods, which are then washed off by the rainfall; partly due to the possible formation of soluble corrosion products that only lightly adhere to the surface, such as zinc chloride $\left(\mathrm{ZnCl}_{2}\right)$, zinc hydroxycarbonate $\left(\mathrm{Zn}_{5}(\mathrm{OH})_{6}\left(\mathrm{CO}_{3}\right)_{2}\right)$ and zinc sulfate $\left(\mathrm{ZnSO}_{4}\right) ;{ }^{20}$ and partly due to ions deposited on the metal surface, such as $\mathrm{K}^{+}, \mathrm{Na}^{+}, \mathrm{Mg}^{2+}$, $\mathrm{Ca}^{2+}$, etc., which were not analyzed in the runoff solutions.

Figure 13 shows the zinc concentration $\left(\mathrm{Zn}^{2+}\right)$ from each rainfall event. It can be observed that the highest

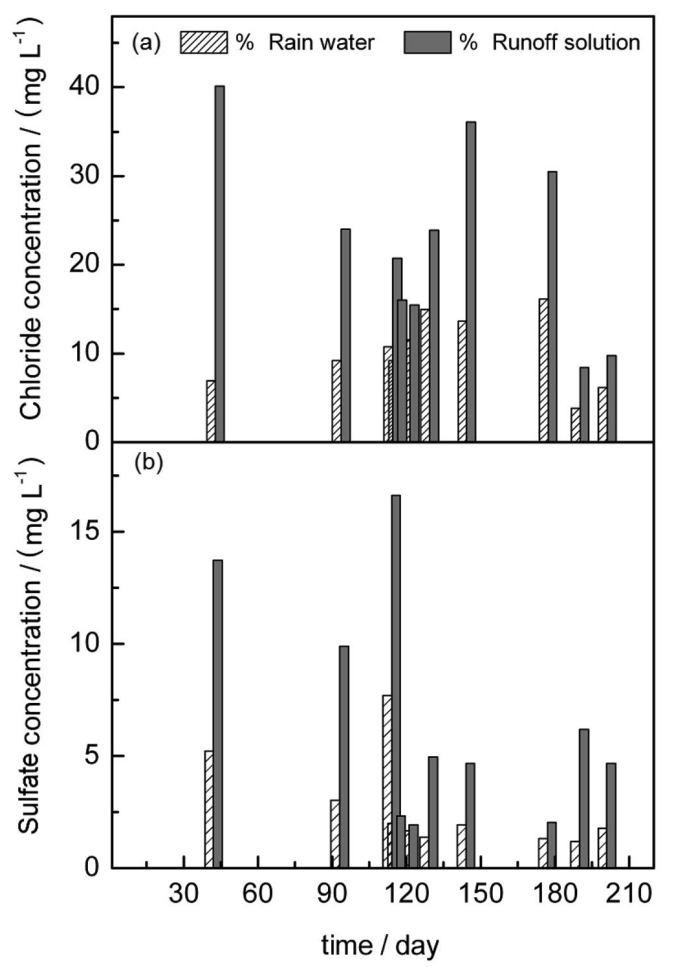

Figure 12. Concentration of (a) chlorides $\left(\mathrm{Cl}^{-}\right)$and (b) sulfates $\left(\mathrm{SO}_{4}^{2-}\right)$ measured in the rainwater and runoff solutions for each rain event.

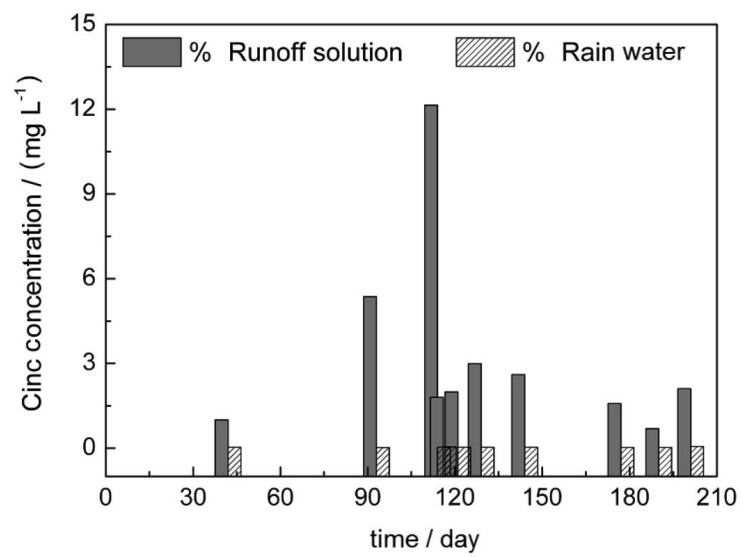

Figure 13. Concentration of $\mathrm{Zn}^{2+}\left(\mathrm{mg} \mathrm{L}^{-1}\right)$ in runoff solutions for each rain event.

$\mathrm{Zn}^{2+}$ concentration is found $\left(12 \mathrm{mg} \mathrm{L}^{-1}\right)$ in the third episode (at 115 days of exposure) due to leaching of the soluble corrosion products. The zinc concentration then decreases with increasing exposure time down to values of approximately $2 \mathrm{mg} \mathrm{L}^{-1}$. This result indicates that the zinc concentration due to the metal surface is strongly influenced by the amount of rainfall, the rainfall duration and the length of time between events.

Figure 14 presents the monthly $\mathrm{Zn}$ mass loss in the runoff solutions. This loss is well correlated with the amount of rainfall, the rainfall periodicity and the duration of the dry periods. During the year, the total $\mathrm{Zn}$ loss from 


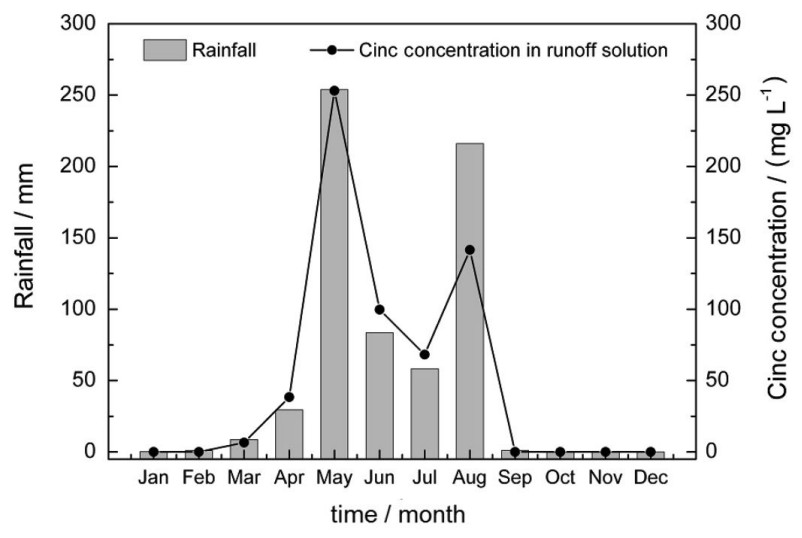

Figure 14. Monthly $\mathrm{Zn}^{2+}$ ion content in the runoff solutions in comparison with the amount of rainfall.

the runoff process is $0.065 \pm 0.004 \mathrm{mg} \mathrm{cm}^{-2}$, equivalent to a $0.07 \mu$ year $^{-1}$ thickness loss (a practically negligible amount). However, it should be noted that the mass loss due to runoff also depends on the stability, porosity and defects of the first corrosion layers formed on the metal as well as on the solubility and adherence of the corrosion products that are formed during the exposure period.

\section{Conclusions}

The atmospheric corrosion and runoff of galvanized steel were studied during a 15 month period at a marine atmospheric station in Valparaiso, Chile, which can be classified for aggressiveness as $\mathrm{C} 3$.

The results show that the $\mathrm{Zn}$ surface mass loss increased over time and that this loss tends towards a constant value after one year of exposure due to the formation of corrosion products on the metal surface, which also increase the corrosion potential over time. The obtained corrosion rate of the galvanized steel after 15 months of exposure to the marine environment was $8.5 \mu \mathrm{m}$ year $^{-1}$. The identified principal corrosion products are zincite $(\mathrm{ZnO})$ and simonkolleite $\left(\mathrm{Zn}_{5}(\mathrm{OH})_{8} \mathrm{Cl}_{2} \cdot \mathrm{H}_{2} \mathrm{O}\right)$, with a secondary product of zinc and sodium chlorohydroxysulfate $\left(\mathrm{NaZn}_{4} \mathrm{Cl}(\mathrm{OH})_{6} \mathrm{SO}_{4} \cdot \mathrm{H}_{2} \mathrm{O}\right)$.

The runoff solutions collected on the 40 days in which rainfall episodes were registered show that the $\mathrm{pH}$ values of the runoff solutions are similar to those of the rainwater and that the chloride content is approximately double that of the rainwater. The latter result is due to the retention of chloride on the galvanized steel surface due to the adsorption or deposition of the $\mathrm{Zn}$ chloride compounds that are formed during the corrosion process. The $\mathrm{pH}$ conditions and chloride content are evidence of the stability of simonkolleite, implying that it functions as a protective barrier against the atmospheric medium.
The zinc concentrations that were measured monthly for the runoff solutions are well correlated with the amount of rainfall, the rainfall periodicity and the duration of the dry periods between rainfall events. During the studied period, the total $\mathrm{Zn}$ loss due to runoff is $0.065 \pm 0.004 \mathrm{mg} \mathrm{cm}^{-2}$, equivalent to a $0.07 \mu \mathrm{m}_{\text {year }}{ }^{-1}$ thickness loss.

\section{Acknowledgments}

The authors acknowledge financial support from the Dirección de Investigación of the Pontificia Universidad Católica de Valparaíso and from the firm B. Bosch, Chile.

\section{References}

1. Veleva, L.; Meraz, E.; Acosta, M.; Mater. and Corros. 2007, 58,348 .

2. Svensson, J.; Johansson, L.; Corros. Sci. 1993, 34, 721.

3. Costa, J.; Vilarrasa, M.; Br. Corr. J. 1993, 28, 117.

4. Wallinder, I. O.; Verbiest, P.; He, W.; Leygraf, C.; Corros. Sci. 1998, 40, 1977.

5. Graedel, T.; J. Electrochem. Soc. 1989, 136, $193 \mathrm{C}$.

6. Quintana, P.; Veleva, L.; Cauich, W.; Pomes, R.; Peña, J.; Appl. Surf. Sci. 1996, 99, 325.

7. Rosales, B. M.; Mapas de Corrosividad Atmosférica de Argentina; CITEFA: Argentina, 1997.

8. Morcillo, M.; Almeida, E.; Rosales, B. M.; Uruchurtu, J.; Marrocos, M.; Corrosión y Protección de Metales en las Atmósferas de Iberoamérica, Parte 1; CYTED: España, 1998.

9. Natesan, M.; Venkatachari, G.; Palaniswamy, N.; Corros. Sci. 2006, $48,3584$.

10. Vilche, J.; Juttner, K.; Lorenz, W.; Kautek, W.; J. Electrochem. Soc. 1989, 136, 3773.

11. Castaño, J.; Botero, C.; Peñaranda, S.; Rev. Metal. 2007, 43, 133.

12. Meraz, E.; Veleva, L.; Acosta, M.; Rev. Metal. 2007, 43, 85.

13. Almeida, E.; Morcillo, M.; Rosales, B.; Br. Corros. J. 2000, 35, 248.

14. Goodwin, F.; Sheir's; Corrosion 2010, 3, 2078.

15. Odnevall, I.; Legraf, C.; Corros. Sci. 1993, 34, 1213.

16. Vera, R.; Guerrero, F.; Delgado, D.; Araya, R.; Rev. Constr. 2009, $8,18$.

17. Volovitch, P.; Vu, T.; Allély, C.; Abdel, A.; Ogle, K.; Corros. Sci. 2011, 53, 2437.

18. De la Fuente, D.; Castaño, J.; Morcillo, M.; Corros. Sci. 2007, 49, 1420.

19. Veleva, L.; Meraz, E.; Acosta, M.; Corr. Sci. Technol. 2010, 45, 76.

20. Veleva, L.; Acosta, M.; Meraz, E.; Corros. Sci. 2009, 51, 2055.

21. Zhang, X.; He, W.; Odnevall, W.; Pan, J.; Leygraf, C.; Corros. Sci. 2002, 44, 2131. 
22. Bertling, S.; Odnevall, I.; Leygraf, C.; Berggren, D.; Sci. Total Environ. 2006, 367, 908.

23. Yadav, A.; Katayama, H.; Noda, K.; Masuda, H.; Nishikata, A.; Tsuru, T.; Corros. Sci. 2007, 49, 3716.

24. ISO 9226, Corrosion of Metals and Alloys. Corosivity of Atmospheres Determination of Corrosion Rate of Standard Specimens for the Evaluation of Corrosivity: International Organization for Standarization: Geneva, Switzerland, 1992.

25. ASTM G50-76, Standard Practice for Conducting Atmospheric Corrosion Test on Metal; ASTM Intern: West Conshohocken, PA, EUA, 2003.

26. ISO 9225, Corrosion of Metals and Alloys, Corrosivity of Atmospheres Methods of Measurement of Pollution; ISO: Geneva, 1991.

27. ISO 8407, Metals and Alloys-Procedures for Removal of Corrosion Products from Corrosion Test Specimens; ISO: Geneva, 1992.
28. Water Standards NCh 2313/1.Of 95, Standard Methods for the Examination the Water and Wastewater; APHA-AWWA-WEF, USA, 1994.

29. Water Standards NCh 409/2, Sulfate Measurement via Residue Drying; APHA-AWWA-WEF, USA, 1994.

30. ISO 9223, Corrosion of Metals and Alloys, Classification of Corrosivity of Atmospheres; ISO: Geneva, 1991.

31. Odnevall, I.; Westdahl, M.; Corros. Sci. 1993, 34, 1231.

32. Qu, Q.; Li, L.; Bai, W.; Yan, C.; Cao, C.; Corros. Sci. 2005, 47, 2832.

33. Qu, Q.; Yan, C.; Wan, Y.; Cao, C.; Corros. Sci. 2002, 44, 2789.

Submitted: October 10, 2012

Published online: March 15, 2013 